\title{
Serial Evaluation of Vasopressin Release and Thirst in Human Pregnancy Role of Human Chorionic Gonadotrophin in the Osmoregulatory Changes of Gestation
}

John M. Davison, Elizabeth A. Shiells, Peter R. Philips, and Marshall D. Lindheimer

Medical Research Council (MRC) Human Reproduction Group, Princess Mary Maternity Hospital, University of Newcastle, Newcastle upon Tyne, NE2 3BD, England; Health Care Research Unit, University of Newcastle, Newcastle upon Tyne, NE2 4AN, England; and Departments of Obstetrics and Gynecology and Medicine, University of Chicago, Chicago, Illinois 60637

\begin{abstract}
Serial studies were designed to characterize changes in osmoregulation throughout gestation. Eight women underwent a 2-h infusion of hypertonic saline before conception, during gestational weeks 5-8, 10-12, and 28-33, and then 10-12 wk postpartum. Basal plasma osmolality ( $\left.\mathbf{P}_{\text {osmol }}\right)$ was already signifcantly decreased by $5-8$ wk $(P<0.001)$ and remained 10 mosmol $\cdot \mathbf{k g}^{-1}$ below nonpregnant values throughout pregnancy. The apparent threshold for AVP release (defined as the abscissal intercept of the regression line relating plasma AVP [ $\mathbf{P}_{\mathbf{A V P}}$ ] to $\mathbf{P}_{\text {osmol }}$ ) was also decreased significantly throughout gestation, as was the osmotic threshold for thirst (derived from analogue scales relating desire to drink to $\left.P_{\text {osmol }}\right)$. The decrement in osmotic thirst threshold appeared to precede that for AVP release, and consistent with this 24-h urine volumes were significantly greater at $5-8$ wk gestation $(P<0.05)$. The slopes of each regression equation defining $P_{A V P}$ vs. $P_{\text {osmol }}$ (whose $r$ values ranged from 0.79 to 0.99 ), very reproducible before and after pregnancy, were similar at 5-8 and 10-12 wk, but were markedly reduced in the third trimester $(P<0.001)$. These volunteers had randomly undergone an additional infusion before conception (both tests in the luteal phase of the menstrual cycle) when 10,000 IU of human chorionic gonadotrophin (hCG) had been given intramuscularly over a 5-d period. Serum hCG values between 0.2 and $3.3 \mathrm{U} \cdot \mathrm{ml}^{-1}$ were lower than usually seen in pregnancy, but the osmotic thresholds for AVP release and thirst decreased by 3 and $4 \mathrm{mosmol} \cdot \mathrm{kg}^{-1}$, respectively $(P<0.05)$. Finally we studied a patient with a molar pregnancy in whom thresholds for hormone release and thirst were both decreased to values resembling normal gestation and remained so for $\sim 6$ wk postevacuation, only normalizing when hCG had virtually disappeared from her serum. In contrast, thresholds increased within the first two puerperal weeks in two women with normal pregnancies. These data demonstrate (a) osmotic thresholds for both AVP release and thirst decrease within the very first gestational weeks; (b) increment in $\mathbf{P}_{\mathbf{A v P}}$ per unit increase in $\mathbf{P}_{\text {osmol }}$ is reduced late in gestation; and (c) hCG may be involved in the osmoregulatory changes of pregnancy.
\end{abstract}

Reprint requests from Great Britain and the Eastern Hemisphere should be addressed to Dr. Davison, MRC Human Reproduction Group. Address those from the Western Hemisphere to Dr. Lindheimer, University of Chicago.

Received for publication 25 June 1987 and in revised form 30 September 1987.

J. Clin. Invest.

(c) The American Society for Clinical Investigation, Inc.

0021-9738/88/03/0798/09 \$2.00

Volume 81, March 1988, 798-806

\section{Introduction}

Body tonicity decreases during human pregnancy, which results in a decrement in plasma osmolality $\left(\mathrm{P}_{\text {osmol }}\right)^{1}$ to $\sim 10$ mosmol $\cdot \mathrm{kg}^{-1}$ below nonpregnant levels. These changes occur during the early weeks of gestation, reach their lowest levels by gestational week 10 , and remain fairly constant thereafter until term (1). On the basis of observations in rodents and a single study in third trimester women we suggested that this new steady state $P_{\text {osmol }}$ was due to parallel decrements in the osmotic thresholds for AVP release and thirst, and indeed, in late human gestation there are decrements in these two thresholds of 6 and $10 \mathrm{mosmol} \cdot \mathrm{kg}^{-1}$, respectively, compared with values recorded postpartum (2-4). The current study was designed to characterize osmotic AVP secretory and thirst thresholds in early human pregnancy to confirm our postulate and to explore if changes observed correlate with any of the known humoral and hemodynamic alterations in normal gestation.

Women wishing to conceive were serially tested. Before conception they were studied twice, once in the basal state and again after having been pretreated with human chorionic gonadotrophin (hCG). They were then retested during gestational weeks 5-8, 10-12, and 28-33, and again postpartum. Also studied was a single patient with a hydatiform mole.

The results demonstrate that the thresholds for AVP release and thirst decline early in the first trimester and explain the rapid decline in body tonicity during the initial months of gestation. Observations made when testing the patient with a molar pregnancy demonstrate that the osmoregulatory alterations of gestation do not require the presence of the fetus. Furthermore, the results produced by hCG administration, combined with those observed in the woman whose hydatiform mole was evacuated, suggest that hCG may be involved in the decrements in the osmotic thresholds that occur in pregnancy. Finally, these serial studies revealed that the "apparent" sensitivity of the AVP secretory response to osmotic stimuli (that is the increase in plasma AVP $\left(P_{A V P}\right)$ per unit increment in $\mathrm{P}_{\text {osmol }}$ ) was decreased in late pregnancy, data which might relate to some of the recently described polyuric syndromes of late gestation.

\section{Methods}

\section{Subjects}

Serial studies were performed on eight normotensive healthy subjects: twice before conception, once between their 5-8, 10-12, and 28-33 gestational weeks, respectively, and again 8-10 wk postpartum when none were breast-feeding or ingesting oral contraceptives. In addition,

1. Abbreviations used in this paper: hCG, human chorionic gonadotrophin; MCR, metabolic clearance rate; $\mathbf{P}_{\mathrm{AVP}}$, plasma AVP; $\mathbf{P}_{\text {osmol, }}$, plasma osmolality. 
one patient with a molar gestation was studied before and four times after surgical evacuation of the hydatiform mole. Two other women studied during the third trimester underwent serial infusion tests in the puerperium. All subjects gave informed consent in writing to protocols approved by both the Ethical Committee of the Newcastle Health Authority and the Clinical Investigation Committee of the University of Chicago, Pritzker School of Medicine. With the exception of the woman with the molar pregnancy, all volunteers had successful pregnancies.

\section{Protocols}

Each test was started at 9 a.m. with the volunteer sitting comfortably in a chair. $30 \mathrm{~min}$ later control blood samples were taken before an infusion of $5 \%$ saline was started at a rate of $0.06 \mathrm{ml} \cdot \mathrm{kg}^{-1} \mathrm{~min}^{-1}$ and continued for $2 \mathrm{~h}$ using a constant-infusion pump. Repeat blood samples were taken at 15 -min intervals and blood pressure was measured at 5-min intervals during the study with an automatic recording device.

During the study thirst was evaluated using an uncalibrated visual linear analogue scale using modifications of methods originally described by Rolls (5-7). Subjects rated their own thirst sensations on an unmarked 10-cm line, 0 representing "not thirsty" and 10 "extremely thirsty". Before the infusion they characterized their own thirst rating and were not automatically given a zero rating. By relating the value for the distance from the zero end of the line to concurrent osmolality, a stimulus-response curve for the thirst mechanism was constructed, its form similar to that relating $P_{A V P}$ to $P_{\text {osmol }}$. In addition, subjects were independently asked to state when they experienced a strong conscious desire to drink.

$h C G$. Women wishing to conceive who had volunteered for the serial pregnancy study underwent two infusion tests, each performed during a luteal phase of their menstrual cycle (confirmed by measuring plasma progesterone levels). 5 and $3 \mathrm{~d}$ before one of the preconception studies (order selected randomly), the volunteer received two intramuscular injections of 5,000 IU of hCG (gonadotrophon L.H., 5,000 IU with solvent; Paines and Byrne Ltd., Greenford, England). The doses were those already in use for certain infertility treatment regimens, and preliminary data $(n=5)$ demonstrated that serum hCG values were highest on day 5 ( $2 \mathrm{~d}$ after second [booster] injection), but declined thereafter.

Patient with a molar gestation. An 18-yr-old caucasian nullipara who presented with a threatened abortion during her 11 th gestational week and was diagnosed by ultrasound as having a molar pregnancy agreed to undergo infusion studies just before evacuation of the mole (when serum hCG levels were $4,000 \mathrm{U} \cdot \mathrm{ml}^{-1}$ ) and 5, 13,41, and $91 \mathrm{~d}$ postevacuation. In addition, two gravidas tested only once in late pregnancy were retested at $4 \mathrm{~d}, 2 \mathrm{wk}, 6 \mathrm{wk}$, and $13 \mathrm{wk}$ during the puerperium.

\section{Assay methods}

Blood for osmolality and electrolyte determinations was collected in chilled heparinized tubes, small portions immediately drawn for microhematocrit determination, and the remainder centrifuged at $4^{\circ} \mathrm{C}$. Osmolality was determined on freshly separated plasma and the remaining sample was stored at $-20^{\circ} \mathrm{C}$ until used (2). Blood for AVP determination was collected in a $10-\mathrm{ml}$ syringe containing $0.1 \mathrm{ml}$ phenanthroline (1-10-phenanthroline monohydrate, Sigma Chemical Co., St. Louis, MO) solution $\left(60 \mathrm{mg} \cdot \mathrm{ml}^{-1}\right)$ and then rapidly added to chilled heparinized tubes, centrifuged in the cold, and extracted within $3 \mathrm{~h}$ of venepuncture. Validation of this technique, which immediately inactivates the high concentrations of cystine aminopeptidase (vasopressinase) present in the plasma of gravidas, is detailed elsewhere (2).

Radioimmunoassay of $A V P$. Details of our extraction technique and assay procedures have been published (2). Briefly, plasma is extracted by a modification of the acetone method and 200- $\mu$ l samples are assayed by a nonequilibrium method. The tracer has a high specific activity $\left(>1,000 \mathrm{Ci} \cdot \mu \mathrm{g}^{-1}\right)$; highly purified AVP (potency 400 $\mathrm{U} \cdot \mathrm{mg}^{-1}$; lot 800207 , Ferring Arzneimittal GmbH, Wittland, FRG) is utilized for iodination and standards, and our antiserum (10169) is specific and sensitive, as assay sensitivity is $0.1 \mathrm{pg}$ per assay tube while its $50 \%$ displacement is $1.6 \mathrm{pg}$ per assay tube.

Radioimmunoassay of $h C G$. Serum hCG was measured by radioimmunoassay using a kit produced by Amersham International (Amersham, United Kingdom). The assay utilizes an antiserum against the beta subunit of hCG, but the whole molecule is used for iodination as well as the standard curve (8). The serum concentrations are expressed as units of $\mathrm{hCG}$ per milliliter $\left(\mathrm{U} \cdot \mathrm{ml}^{-1}\right)$ of the World Health Organization International Reference Preparation for Immunoassay (73:537). Crossreactivity with luteinizing hormone is only $2.5 \%$ on a molar basis. Determinations on serum samples obtained from women in the follicular phase of their cycles $(n=30)$ and men $(n$ $=10$ ) gave values that are consistently below the assays level of detection $\left(0.005 \mathrm{U} \cdot \mathrm{ml}^{-1}\right)$. Two values $>0.01 \mathrm{U} \cdot \mathrm{ml}^{-1}$ after a missed period are diagnostic of early pregnancy.

Other analytical procedures included determination of osmolality by freezing point depression and sodium by flame photometry.

\section{Statistical analyses}

The primary objective of these analyses was to assess whether the relationships between $P_{\text {osmol }}$ and $P_{A V P}$ or between $P_{o s m o l}$ and thirst changed with the administration of hCG or during the course of pregnancy. The data points $(n=9)$ obtained during the infusion of each patient $(n=8)$ at each test occasion $(n=6)$ were used in separate least-squares linear regressions to obtain individual slopes and to calculate the abscissal intercepts or threshold values. Analyses of variance were then performed using the generalized linear interactive model on the values so obtained to investigate the significance of the change in the relationships at the different test occasions (9). Where a significant change $(P<0.05)$ between test occasions was detected a value for the least significant difference between means at the $5 \%$ probability level was calculated from the residual mean square using the method of Snedecor and Cochran (10).

Other paired comparisons were performed using Student's $t$ test. For all analyses, values of $P \leq 0.05$ were considered significant. All data are given as mean \pm SD.

\section{Results}

\section{Serial infusions throughout gestation}

Studies were performed on eight volunteers, whose ages ranged from 22 to $31 \mathrm{yr}$; five of whom were nulliparas and the remainder multigravidas (one to three previous gestations). Fig. 1 depicts two representative subjects (one a nullipara [D.S.], the second a multigravida [B.P.]), and summarizes their performances in six serial tests. Basal tonicity decreased before conception during hCG treatment in both women (4 and 9 mosmol $\cdot \mathrm{kg}^{-1}$, respectively), and was even lower at gestational week 5 to 8 , and remained so throughout gestation. The slow infusion of $5 \%$ saline resulted in gradual rises in $P_{\text {osmol }}$ and $P_{A V P}$ before conception as well as during and after pregnancy. The similarity of the response during the preconception (untreated) and postpartum infusions should be noted (the slopes of the regression lines characterizing $P_{A V P}$ vs. $P_{\text {osmol }}$ were 0.54 and 0.60 before, compared with 0.48 and 0.62 after pregnancy in subjects D.S. and B.P., respectively, with correlation coefficients ( $r$ values) ranging from 0.87 to 0.96 ). Note further that the increments in AVP levels in relation to increases in $\mathbf{P}_{\text {osmol }}$ were considerably lower during the third trimester infusions (slopes at 6, 12, and $33 \mathrm{wk}$ were $0.54,0.47$, and 0.22 , respectively, in subject D.S., and $0.55,0.56$, and 0.42 at 8,11 , and 28 wk in subject B.P.; all $r$ values 0.79 to 0.97 ). Not shown, the osmotic thresholds for thirst were similar before and after pregnancy in both D.S. and B.P., but decreased 5 and 9 mos- 

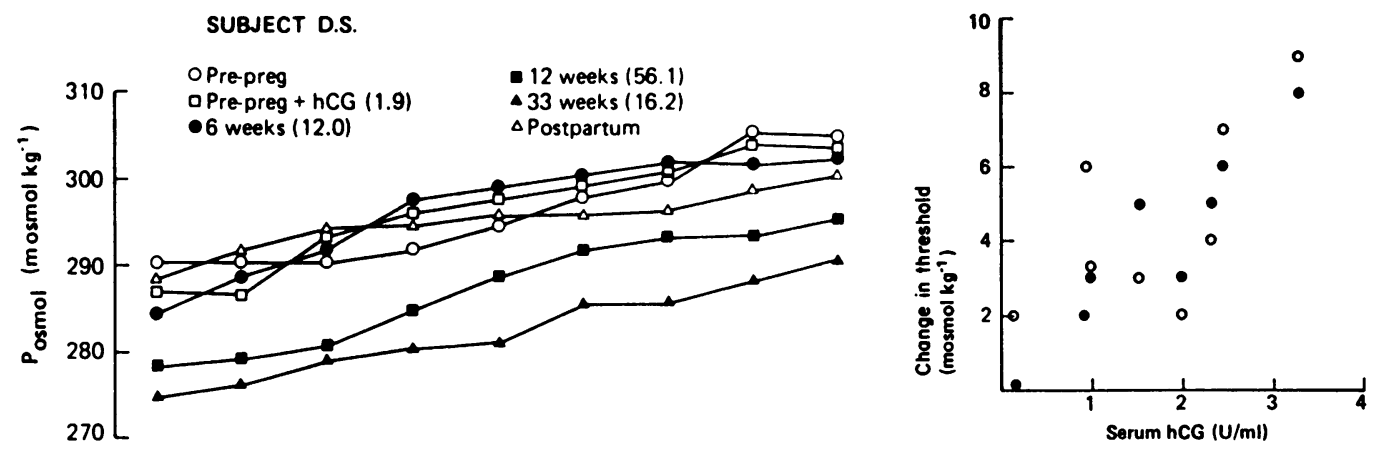

Figure 2. Decrements $(\Delta$ osmol) in osmotic thresholds for AVP release (•) and thirst (o) after hCG treatment in eight women. Both control and hCG tests were performed randomly during the luteal phase of the menstrual cycle (see

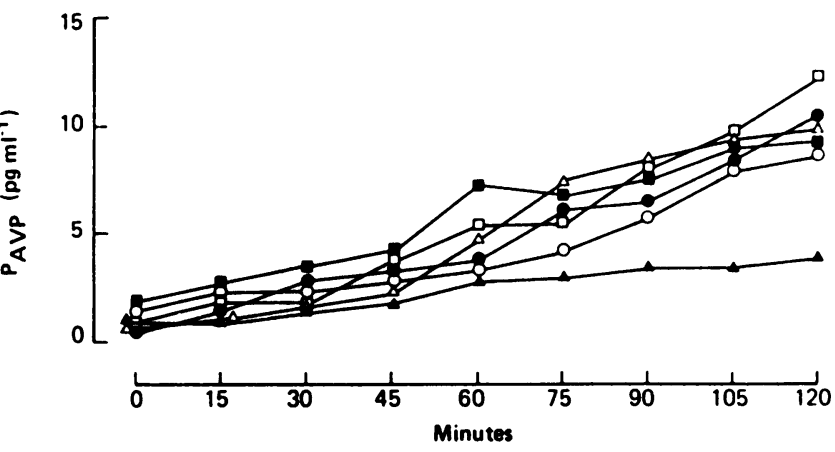

SUBJECT B.P.
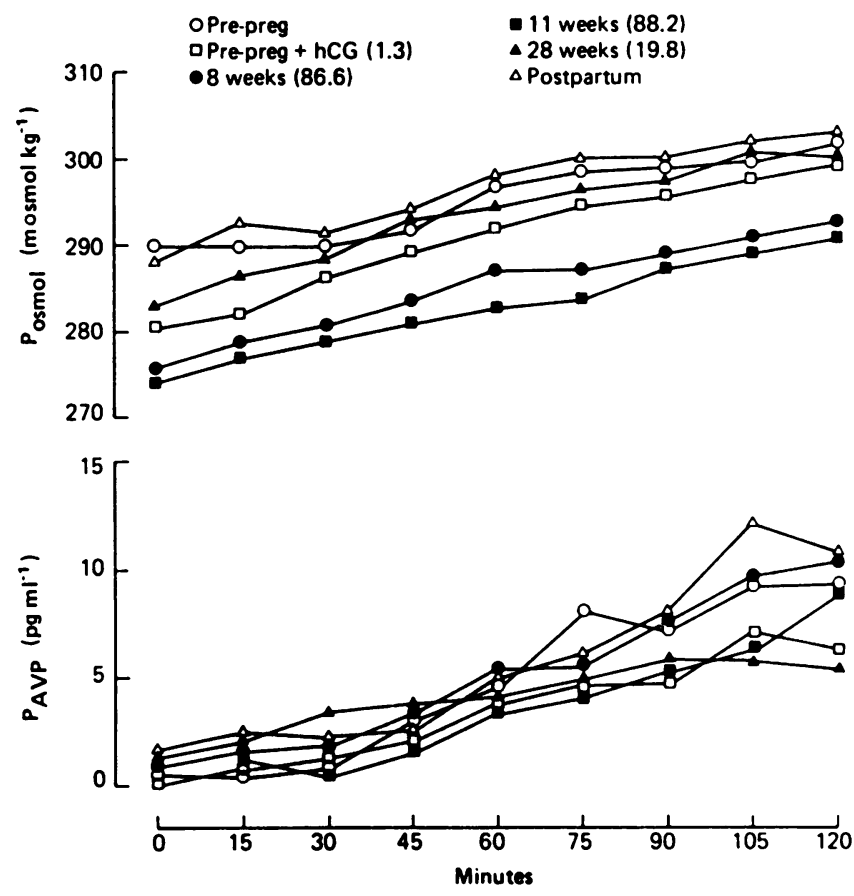

Figure 1. Representative response of $\mathrm{P}_{\text {osmol }}$ and $\mathrm{P}_{\mathrm{AVP}}$ during the $2 \mathrm{~h}$ of hypertonic saline infusion in subjects D.S. and B.P. studied serially on six different occasions before, during, and after pregnancy (preg). Figures in brackets are serum hCG concentrations $\left(\mathrm{U} \cdot \mathrm{ml}^{-1}\right)$.

$\mathrm{mol} \cdot \mathrm{kg}^{-1}$ after hCG, 10 and $13 \mathrm{mosmol} \cdot \mathrm{kg}^{-1}, 10$ and 13 mosmol $\cdot \mathrm{kg}^{-1}$, and 11 and $10 \mathrm{mosmol} \cdot \mathrm{kg}^{-1}$ at the 6-8-, 11-12-, and 28-33-wk tests, respectively (decreases with hCG, $P<0.01$ in D.S., all other decrements, $P<0.001$ ).

Data from all eight women are summarized in Tables I, II, and III. Body tonicity was significantly lower as early as 5-8 wk gestation and remained at these levels throughout preg-

nancy, with mean $\mathrm{P}_{\text {osmol }}$ averaging $280 \pm 3.4,279 \pm 5.6$, and $279 \pm 5.0 \mathrm{mosmol} \cdot \mathrm{kg}^{-1}$ at the start of the 5-8-, $10-12-$, and 28-33-wk tests, respectively, compared with nonpregnant level of $290 \pm 2.2 \mathrm{mosmol} \cdot \mathrm{kg}^{-1}$ (Table I). Pretreatment with hCG before conception also decreased $P_{\text {osmol }}(285 \pm 3.3$ mos$\mathrm{mol} \cdot \mathrm{kg}^{-1} ; P<0.01$ ), but the decrements were $\sim 50 \%$ of those occurring with pregnancy. Note, however, that the regimen utilized resulted in serum hCG levels ranging from 0.2 to 3.3 $\mathrm{U} \cdot \mathrm{ml}^{-1}$, which were considerably below those measured during gestation, where lowest values at any test period ranged from 12.0 to $51.1 \mathrm{U} \cdot \mathrm{ml}^{-1}$. Even over this small range of hCG values, however, the decrements in AVP secretory and thirst thresholds seemed to relate to circulating hCG levels (Fig. 2).

The slow infusion of $5 \%$ saline resulted in a gradual rise in body tonicity (always $<2 \% \cdot \mathrm{h}^{-1}$ ) during each phase of the serial study (Table I). Mean arterial pressure was stable through the first $90 \mathrm{~min}$ but then increased by $8.7 \pm 2.4 \mathrm{mmHg}$. Hematocrit decreased by 2-5\%, again mainly towards the end of the infusion. The increments in $P_{\text {osmol }}$ from before to the end of the 2-h infusions were always accompanied by concomittant increases in $\mathrm{P}_{\mathrm{AVP}}(P<0.001)$.

All the data points for changes in $P_{A V P}$ with elevation of $P_{\text {osmol }}$ from each patient on each test occasion are shown in Fig. 3. The results of the linear regression analyses performed on the data from each individual hypertonic saline infusion are presented in Table II. In each case there was a statistically significant linear relationship between $\mathrm{P}_{\text {osmol }}$ and $\mathrm{P}_{\mathrm{AVP}}$, with $r$ values ranging from 0.79 to 0.99 . Extrapolation of each individual regression line to the abscissal intercept define the osmotic thresholds for AVP secretion. ${ }^{2}$ Means of the eight individual slopes and thresholds obtained at each of the six test occasions are summarized in Table III. The threshold was slightly decreased by hCG treatment $(P<0.05)$, and markedly lower throughout pregnancy $(P<0.001)$ compared with nonpregnant control levels.

2. There is debate as to whether or not the osmoreceptor truly exhibits threshold behavior or functions in a continuous manner (11-14). Certainly there is a $P_{\text {osmol }}$ under which $P_{A V P}$ is usually undetectable and urine osmolality is minimal, and above which hormone secretion is obviously stimulated. In the latter circumstances the AVP-osmolality relationship can be precisely defined by a linear equation. We have chosen to call the osmolar abscissal intercept of the regression equation relation of $\mathbf{P}_{\mathbf{A V P}}$ to $\mathbf{P}_{\text {osmol }}$ the apparent secretory threshold for AVP. In these studies an analysis of variance produced a significant effect for test occasion $\left(\mathrm{F}_{5335}=11.11 P<0.001\right.$; least significant difference between mean thresholds was $4.6 \mathrm{mosmol} \cdot \mathrm{kg}^{-1}$ at $P<0.05$ ). 


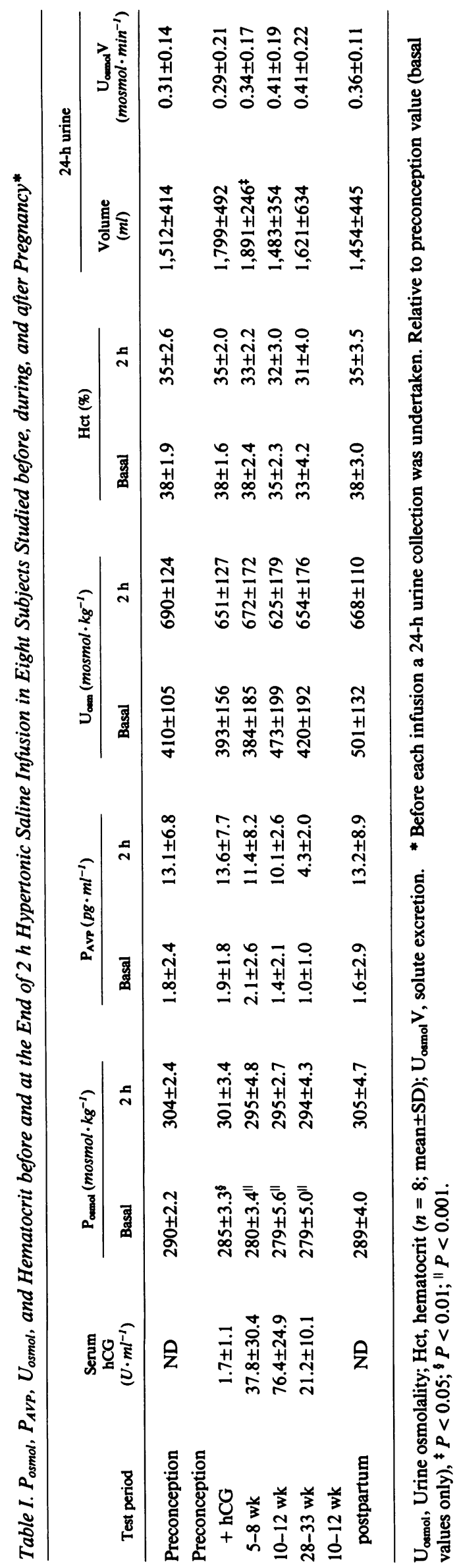

Of interest, the slope for the regression equations which defines the "apparent" sensitivity of the osmotic response $\left(\mathrm{P}_{\mathrm{AVP}}\right.$ vs. $\left.\mathrm{P}_{\text {osmol }}\right)$ was decreased by $>50 \%$ during the third trimester, ${ }^{3}$ although the osmotic threshold for hormonal release was similar to that measured earlier in pregnancy (Table III). The slopes measured before and after pregnancy $(0.61$ and 0.59 , respectively), like the osmotic thresholds for hormone release (285 and $286 \mathrm{mosmol} \cdot \mathrm{kg}^{-1}$, respectively), were also similar before and after pregnancy, confirming that these values remain stable over time in nonpregnant populations and underscore the reproducibility of the infusion technique in our hands.

Table III also contains mean thresholds and slopes derived from the regression lines comparing thirst to $P_{\text {osmol }}$ during each phase of the study. Treatment with hCG resulted in decrements of $4.1 \pm 2.9 \mathrm{mosmol} \cdot \mathrm{kg}^{-1}(P<0.05)$ and values were markedly decreased throughout pregnancy $(280 \pm 3.4$ mos$\mathrm{mol} \cdot \mathrm{kg}^{-1}$ at $5-8 \mathrm{wk}, 280 \pm 3.4 \mathrm{mosmol} \cdot \mathrm{kg}^{-1}$ at $10-12 \mathrm{wk}$, and $279 \pm 2.7 \mathrm{mosmol} \cdot \mathrm{kg}^{-1}$ at $28-33 \mathrm{wk}$; all values were $P$ $<0.001$ ). (The least significant detectable difference in thirst thresholds was $2.4 \mathrm{mosmol} \cdot \mathrm{kg}^{-1}\left(F_{5,35}=35.21, P<0.001\right)$, and there was no difference between slopes $\left(F_{5^{\prime} 35}=1.22 \mathrm{NS}\right)$ across test occasions). The threshold normalized after gestation, levels postpartum being identifical to those measured before conception $\left(290 \mathrm{mosmol} \cdot \mathrm{kg}^{-1}\right)$. An analysis of variance demonstrated no change in the difference between AVP secretory threshold and thirst threshold on the six test occasions $\left(F_{5,35}=0.89 \mathrm{NS}\right)$, but thirst threshold was always greater than AVP secretory threshold, the mean difference being 3.6 mosmol $\cdot \mathrm{kg}^{-1}$.

In Table I are 24-h urine volumes, which were slightly but significantly $(P<0.05)$ increased at 5-8 wk, although daily solute excretion was similar at each study phase. In addition, the volumes of water ingested (to satiety) after the 2-h hypertonic infusion were significantly greater $(P<0.01)$ both at $5-8$ and 10-12 wk gestation (Table III).

\section{Studies in the patient with a molar pregnancy}

Table IV summarizes data obtained before and up to $95 \mathrm{~d}$ after evacuation of a hydatiform mole in patient A.W. Basal $P_{\text {osmol }}$ was markedly reduced below norms for nongravid women when first studied (11 wk gestation) at a time when serum hCG was $4,000 \mathrm{U} \cdot \mathrm{ml}^{-1}$. Body tonicity remained decreased through her 41 st postevacuation day, at a time when circulating hCG was still elevated. Hypertonic saline infusion tests before suction curettage and at 5,13, and $41 \mathrm{~d}$ afterwards revealed decreased osmotic thresholds for AVP release and thirst, resembling those during normal gestation. When tested on day 95 , circulating hCG had virtually disappeared $\left(0.01 \mathrm{U} \cdot \mathrm{ml}^{-1}\right)$, while basal $P_{\text {osmol }}$ and the osmotic threshold had returned to nonpregnant levels (Table IV and Fig. 4). Fig. 4 and Table V also contain data from two women who had normal term deliveries (ages 26 and $27 \mathrm{yr}$, one nullipara (K.T.) and one multipara [B.B.]). Each was tested in the third trimester and four times in the puerperium. Basal $P_{\text {osmol }}$ had increased by postpartum day 4 (as had the osmotic thresholds for hormone release and thirst) and was normal by puerperal week 2 .

3. An analysis of variance of these slopes demonstrated a significant effect of test occasion $\left(F_{5,35}=8.93, P<0.001\right.$; least significant difference between mean slopes was 0.16 at $P<0.05$ ). 

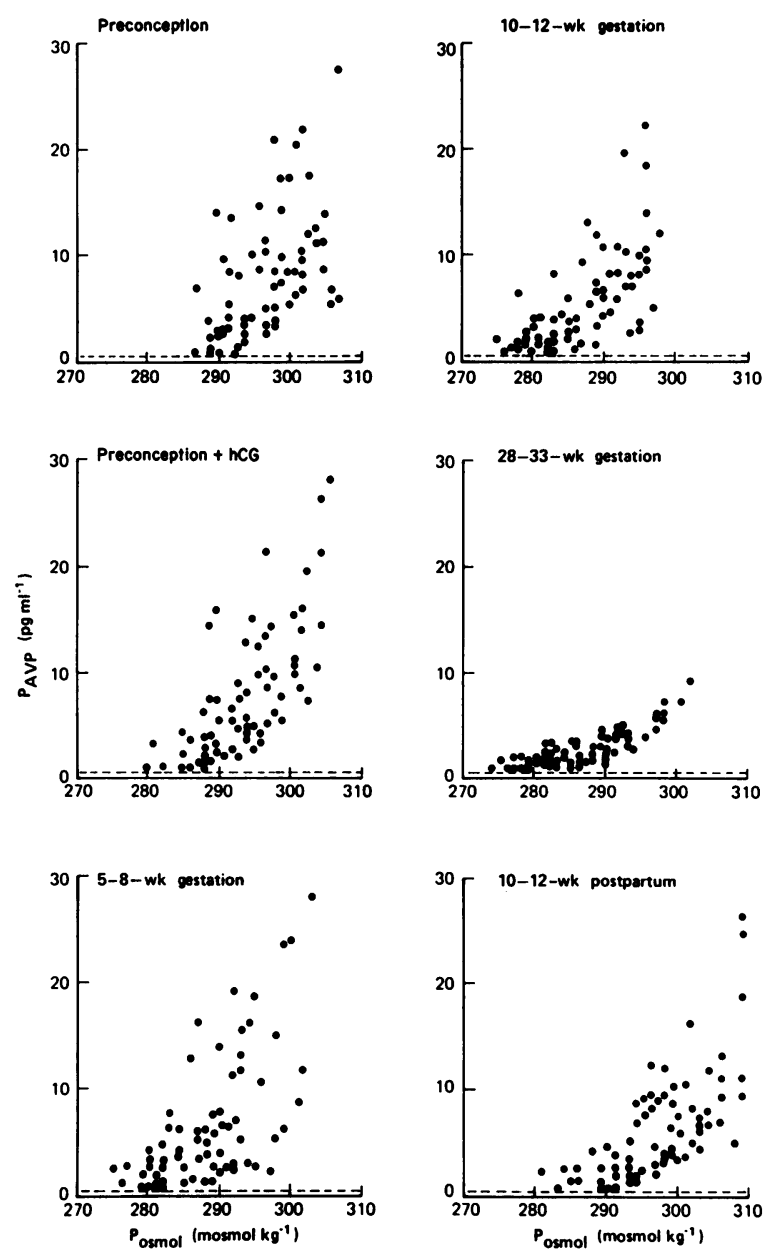

Figure 3. Relationship of $\mathbf{P}_{A V P}$ to $P_{\text {osmol }}$ during a 2-h hypertonic saline infusion in eight women studied on six separate occasions: before conception with and without hCG; 5-8 wk, 10-12 wk, and 28-33 wk gestation; and 10-12 wk postpartum. Each point is an individual plasma determination (there were nine samples per infusion in each subject). Dashed line on each figure represents the lower limit of detection for AVP $\left(0.5 \mathrm{pg} \cdot \mathrm{ml}^{-1}\right)$. The slopes, abscissal intercepts, and correlation coefficients for each individual infusion are given in Table II; the mean osmotic thresholds for AVP release are thirst as given in Table III.

\section{Discussion}

Previously we demonstrated that osmotic thresholds for AVP release and thirst were decreased in the third trimester, hypothesizing that these changes had actually occurred early in pregnancy and were the reason for the decrease in body tonicity that takes place during the very first weeks of gestation (2). We also noted that maintenance of this lower steady state $P_{\text {osmol }}$ within a narrow range with normal 24-h urine volumes required parallel decrements of the osmotic AVP secretory and thirst thresholds. Otherwise $P_{\text {osmol }}$ would remain near nonpregnant levels despite considerable AVP secretion if the gravida was not stimulated to drink at a lower level of body tonicity. On the other hand, if the thirst threshold alone decreased, hormonal secretion would cease after small decrements in osmolality, the gravida would enter a state of continued water diuresis, and considerable polydipsia would be required to maintain the lower $P_{\text {osmol }}$. The present observations fulfill these requirements since both thresholds are significantly decreased as early as 5-8 wk gestation, and all are at their lowest values by the 10-12-wk period. The data also suggest that the decrement in the osmotic thirst threshold may precede that for AVP release, the former having already reached its lowest level by the 5-8-wk period while that for AVP declines still further (albeit nonsignificantly) over the next $4 \mathrm{wk}$. In addition, 24-h urinary volumes are slightly and significantly increased at 5-8 wk (while solute excretion is similar to those in the other test periods). This would be expected if, indeed, the decline in the thirst threshold was earlier than that for AVP release.

The performance of serial studies demonstrated significant changes in the "apparent" sensitivity to osmotic stimuli between early and late pregnancy, as the slope of the regression line characterizing $P_{A V P}$ vs. $P_{\text {osmol }}$ was lower in the third trimester, while that measured during the first trimester were similar to nonpregnant values. These results at first appear at variance with our previous study of women studied in the third trimester and 10-12 wk postpartum, in which the slopes during each period were similar. At that time, however, we noted that "although the postpartum slope was not significantly different from the slope noted during pregnancy, it was slightly steeper," suggesting the need for further studies (2). Since then, we have altered our protocols, increasing the number of blood samples over the 2-h infusion from six to eight and utilized an analogue scale to determine the thirst threshold. In addition, aware that an excessively rapid increment in $\mathbf{P}_{\text {osmol }}$ may result in exaggerated AVP secretion, we carefully controlled the infusion rate in each study to ensure that rise in tonicity was always $<2 \% \cdot h^{-1}$. Such steps have refined our capabilities and increased the precision of the infusion tests as evidenced by the $r$ values of the individual regression lines and the reproducibility of the studies performed before and after pregnancy (Table II). With these improvements the decrease in the osmotic sensitivity during late pregnancy becomes more obvious.

Reasons for the decrease in the apparent osmotic sensitivity are not obvious from our data. There could be a true decrease in the AVP response to a rise in tonicity, as may occur in nongravid patients with primary aldosteronism and other hypervolemic states (15). Intravascular volume is increased $30-40 \%$ in third trimester women and this might cause suppression of the osmotic response. Such an explanation, however, would contrast with observations in rodents, which consistently indicate that the increments in absolute volume occurring during gestation are "sensed" as effectively normal or slightly decreased $(16,17)$.

Another possible explanation for the shallower slope is that the osmotically stimulated hormonal response is not decreased but actually normal or even increased, but the metabolic clearance rate (MCR) of AVP is markedly enhanced. In favor of this latter suggestion is our recent observation that the MCR is increased three- to fourfold in late gestation, but not at all or only minimally so in the first trimester (18). Furthermore, these increments seem to parallel the marked increases in levels of circulating cystine-aminopeptidase (vasopressinase), which are manyfold those noted at 10-12 wk (Davison, J. M., and $M$. D. Lindheimer, unpublished results). In this respect pregnant Sprague-Dawley rats, whose body tonicity also decreases $\sim 10 \mathrm{mosmol} \cdot \mathrm{kg}^{-1}$, accompanied by decrements in the osmotic threshold for AVP release, experience little or no change in the slope of the regression lines comparing $P_{A V P}$ with 
Table II. Results of Regression Analyses of the Relationship between $P_{A V P}$ and $P_{\text {osmol }}{ }^{*}$

\begin{tabular}{|c|c|c|c|c|c|c|}
\hline Subject & Preconception & $\begin{array}{l}\text { Preconception } \\
+ \text { hCG }\end{array}$ & $5-8$ wk gestation & 10-12 wk gestation & 28-30 wk gestation & $\begin{array}{c}10-12 \mathrm{wk} \\
\text { postpartum }\end{array}$ \\
\hline \multicolumn{7}{|l|}{ Slope } \\
\hline 1 & 0.42 & 0.50 & 0.44 & 0.38 & 0.10 & 0.40 \\
\hline 2 & 0.36 & 0.39 & 0.37 & 0.38 & 0.15 & 0.29 \\
\hline 3 & 1.02 & 0.90 & 0.86 & 0.75 & 0.38 & 1.15 \\
\hline 4 & 0.60 & 0.54 & 0.55 & 0.56 & 0.42 & 0.62 \\
\hline 5 & 0.75 & 0.77 & 0.78 & 0.68 & 0.23 & 0.65 \\
\hline 6 & 0.54 & 0.52 & 0.54 & 0.47 & 0.22 & 0.48 \\
\hline 7 & 0.70 & 0.64 & 0.69 & 0.69 & 0.20 & 0.58 \\
\hline 8 & 0.53 & 0.50 & 0.52 & 0.40 & 0.12 & 0.53 \\
\hline Mean & $\underline{0.61}$ & $\underline{0.59}$ & $\underline{0.59}$ & $\underline{0.53}$ & $\underline{0.23}$ & $\underline{0.59}$ \\
\hline \multicolumn{7}{|c|}{ Abscissal intercept } \\
\hline 1 & 284 & 284 & 272 & 271 & 274 & 288 \\
\hline 2 & 291 & 285 & 279 & 281 & 280 & 289 \\
\hline 3 & 281 & 278 & 272 & 271 & 272 & 280 \\
\hline 4 & 288 & 280 & 279 & 277 & 277 & 288 \\
\hline 5 & 290 & 285 & 283 & 281 & 278 & 288 \\
\hline 6 & 284 & 279 & 279 & 278 & 277 & 287 \\
\hline 7 & 280 & 278 & 276 & 273 & 272 & 279 \\
\hline 8 & 286 & 283 & 280 & 274 & 276 & 285 \\
\hline Mean & $\underline{285}$ & $\underline{282}$ & $\underline{278}$ & $\underline{276}$ & $\underline{276}$ & $\underline{286}$ \\
\hline \multicolumn{7}{|c|}{ Correlation coefficient } \\
\hline 1 & 0.90 & 0.93 & 0.79 & 0.99 & 0.95 & 0.92 \\
\hline 2 & 0.84 & 0.95 & 0.91 & 0.94 & 0.85 & 0.87 \\
\hline 3 & 0.85 & 0.85 & 0.95 & 0.88 & 0.88 & 0.84 \\
\hline 4 & 0.95 & 0.96 & 0.96 & 0.97 & 0.89 & 0.96 \\
\hline 5 & 0.92 & 0.93 & 0.98 & 0.93 & 0.94 & 0.97 \\
\hline 6 & 0.85 & 0.79 & 0.92 & 0.91 & 0.89 & 0.90 \\
\hline 7 & 0.88 & 0.96 & 0.90 & 0.89 & 0.89 & 0.86 \\
\hline 8 & 0.86 & 0.85 & 0.82 & 0.92 & 0.85 & 0.92 \\
\hline Mean & $\underline{0.87}$ & $\underline{0.89}$ & $\underline{0.89}$ & $\underline{0.93}$ & $\underline{0.89}$ & $\underline{0.90}$ \\
\hline
\end{tabular}

* During hypertonic saline infusions in individual subjects $(n=8)$ studied serially on six occasions before, during, and after pregnancy expressed in form $\mathbf{P}_{\mathrm{AVP}}=$ slope $\left(\mathrm{P}_{\text {osmol }}-\right.$ abscissal intercept $)$.

Table III. Mean Results of the Relationship between $P_{o s m o l}$ and $P_{A V P}$ or Thirst

\begin{tabular}{|c|c|c|c|c|c|c|c|c|c|}
\hline \multirow[b]{2}{*}{ Test period } & \multicolumn{3}{|c|}{ Osmotic threshold for AVP release } & \multicolumn{3}{|c|}{ Osmotic thirst threshold } & \multirow{2}{*}{$\begin{array}{c}P_{\text {ommol }} \text { where } \\
\text { conscious desire } \\
\text { to drink occurred } \\
\left(\mathrm{mosmol} \cdot \mathrm{kg}^{-1}\right)\end{array}$} & \multicolumn{2}{|c|}{$\begin{array}{l}\text { Water ingested at end of } \\
\text { infusion }(m l)^{s}\end{array}$} \\
\hline & $\begin{array}{c}\mathrm{P}_{\text {ommol }} \mathbf{F}^{*} \\
\left(\text { mosmol } \cdot \mathrm{kg}^{-l}\right)\end{array}$ & Slope $^{\ddagger}$ & $r^{*}$ & $\underset{\left(m o s m o l \cdot \mathrm{kg}^{-1}\right)}{\mathrm{P}_{\text {oumol }}}$ & Slope & $r$ & & Total & $\begin{array}{c}\text { Per kilogram } \\
\text { bodyweight }\end{array}$ \\
\hline Preconception & 285 & 0.61 & 0.87 & 290 & 0.52 & 0.97 & 298 & $370 \pm 82$ & $6.12 \pm 1.31$ \\
\hline \multicolumn{10}{|l|}{ Preconception } \\
\hline$+\mathrm{hCG}$ & $282^{\prime \prime}$ & 0.59 & 0.89 & $286^{\prime \prime}$ & 0.47 & 0.97 & $293^{\prime \prime}$ & $422 \pm 66$ & $6.88 \pm 1.7$ \\
\hline $5-8$ wk & $278^{* *}$ & 0.59 & 0.89 & $280^{* *}$ & 0.49 & 0.97 & $288^{* *}$ & $499 \pm 62^{\prime}$ & $8.21 \pm 1.35^{\top}$ \\
\hline $10-12$ wk & $276^{* *}$ & 0.53 & 0.93 & $280^{* *}$ & 0.45 & 0.97 & $288^{* *}$ & $501 \pm 53^{\prime}$ & $8.09 \pm 1.33^{1}$ \\
\hline $28-33$ wk & $276^{* *}$ & 0.23 & 0.89 & $279^{* *}$ & 0.47 & 0.97 & $288^{* *}$ & $469 \pm 61$ & $6.49 \pm 0.95$ \\
\hline \multicolumn{10}{|l|}{$10-12$ wk } \\
\hline postpartum & 286 & 0.59 & 0.90 & 290 & 0.45 & 0.96 & 299 & $375 \pm 67$ & $5.92 \pm 1.11$ \\
\hline
\end{tabular}

* During 2-h hypertonic saline infusion for eight subjects studied serially before, during, and after pregnancy. Results of regression analyses are expressed in the form $P_{A V P}$ or thirst $=$ slope $\left(P_{\text {osmol }}-\right.$ abscissal intercept $)$. Also given are mean values for $P_{\text {osmol }}$ at which conscious desire to drink occurred and mean $( \pm \mathrm{SD})$ values for water ingested at end of infusion. ${ }^{\ddagger}$ Individual data are given in Table II. $\$$ Water drank to satiety. Relative to preconception value, " $P<0.05$; $^{\top} P<0.01$; $^{* *} P<0.001$. 
Table IV. Osmoregulation before and after Suction Curettage Removal of a Hydatidiform Mole (Patient A.W.)

\begin{tabular}{|c|c|c|c|c|c|c|c|c|}
\hline \multirow[b]{2}{*}{ Gestation } & \multirow[b]{2}{*}{$\underset{\left(\mathrm{mosmol} \cdot \mathrm{kg}^{-1}\right)}{\text { Basal } \mathrm{P}_{\text {omol }}}$} & \multirow[b]{2}{*}{$\begin{array}{l}\text { Serum hCG } \\
\left(U \cdot m l^{-1}\right)\end{array}$} & \multicolumn{3}{|c|}{ Osmotic threshold for AVP release } & \multicolumn{3}{|c|}{ Osmotic thirst threshold } \\
\hline & & & $\begin{array}{c}\mathrm{P}_{\text {ommol }} \\
\left(\mathrm{mosmol} \cdot \mathrm{kg}^{-1}\right)\end{array}$ & Slope & $r$ & $\begin{array}{c}\mathrm{P}_{\text {oumol }} \\
\left(\mathrm{mosmol} \cdot \mathrm{kg}^{-1}\right)\end{array}$ & Slope & $r$ \\
\hline \multicolumn{9}{|l|}{$w k$} \\
\hline \multicolumn{9}{|c|}{ Pre-curettage } \\
\hline 11 & 277 & 4,000 & 275 & 0.51 & 0.93 & 278 & 0.57 & 0.99 \\
\hline \multicolumn{9}{|c|}{ Post-curettage } \\
\hline $4^{*}$ & 279 & 34.7 & 276 & 0.63 & 0.98 & 278 & 0.72 & 0.97 \\
\hline 13 & 282 & 6.1 & 277 & 0.65 & 0.97 & 278 & 0.47 & 0.92 \\
\hline 41 & 280 & 1.5 & 278 & 0.62 & 0.92 & 280 & 0.53 & 0.95 \\
\hline 95 & 288 & 0.01 & 285 & 0.69 & 0.96 & 286 & 0.64 & 0.95 \\
\hline
\end{tabular}

See Table II and text for explanation of derivation of terms. * Days after uterine evacuation.

$\mathbf{P}_{\text {osmol }}$ when values during either early or late gestation are compared with those of age-matched virgins $(3,19)$. This species produces no detectable vasopressinase.

Mechanisms responsible for the decreases in osmotic thresholds during pregnancy are unknown. Furthermore, this phenomenon is species dependent, body tonicity decreasing markedly in both rodent and human pregnancy but remaining unaltered in gravid sheep $(3,4,19,20)$. In the rat we have systematically tested the roles of several hormones whose levels increase during gestation, and investigated the effect of hemodynamic and volume changes that occur in rodent pregnancy and have failed to implicate estrogens, progesterone, prolactin, components of the renin-angiotensin, or opioids in the observed decrements in $P_{\text {osmol }}$ (19). Similarly, decreases in "effective" volume or blood pressure are not effectors of these changes $(16,21)$. Thus, in the present studies it was of interest to observe that pretreatment with hCG did result in significant, albeit small, decreases in body tonicity and the osmotic thresholds for thirst and AVP release. The reason for these minimal changes may be that serum hCG levels produced in our protocol were extremely low, compared with values measured throughout pregnancy $(8,22,23)$, as the amount in-

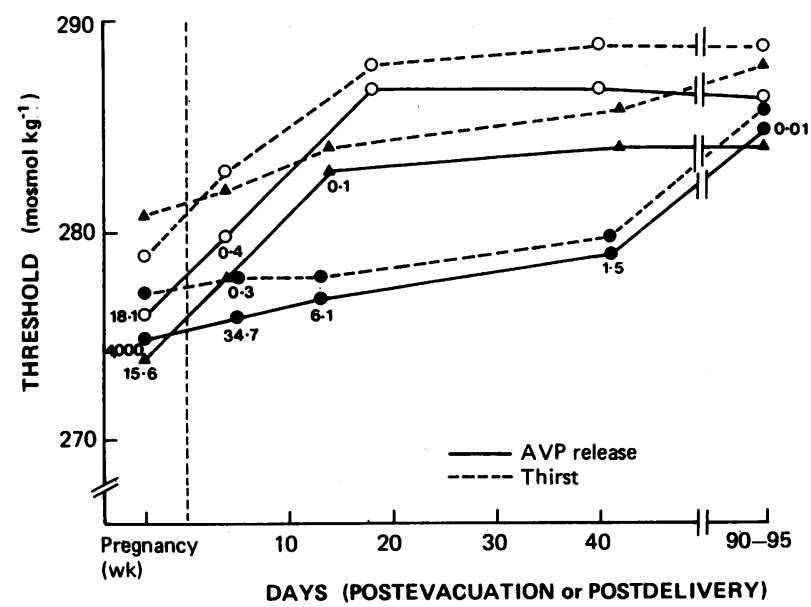

Figure 4. Osmotic threshold for AVP release (-) and thirst (- - -) in the patient with a hydatidiform mole (๑), compared with two normal gravidas ( $O$ and $\Delta)$. Numbers by symbols are serum hCG levels $\left(\mathrm{U} \cdot \mathrm{ml}^{-1}\right)$. Further details are given in Tables IV and $\mathrm{V}$. jected was limited by safeguards established for hCG use in infertility clinics. Future studies may involve cautious increments in hCG dose regimens to establish if $P_{\text {osmol }}$ will decrease further. That hCG may be involved in the observed increments in thresholds is further suggested by the data from the subject with a molar gestation, and here the results are less equivocal (Table III and Fig. 3). Her body tonicity and osmotic thresholds were initially markedly depressed to levels seen in normal gestation. $\mathbf{P}_{\text {osmol }}$ then remained depressed until circulating hCG decreased to $0.1 \mathrm{U} \cdot \mathrm{ml}^{-1}$, while hormone concentrations and osmotic thresholds in the two women with uneventful term deliveries normalized by 2 wk postpartum $(24,25)$.

Although a role for hCG in the osmoregulatory changes appears interesting, a causal link remains to be established and many questions remain. The rodent, for example, which experiences gestational osmoregulatory changes similar to humans, does not seem to produce an hCG-like hormone. On the other hand, injection of hCG into virgin rats with intact ovaries (but not in ovariectomized animals) reduces $P_{\text {osmol }}$ significantly (Barron, W. M., and M. D. Lindheimer, unpublished results). Furthermore, while hCG reduces $\mathrm{P}_{\text {osmol }}$ during the luteal phase of the menstrual cycle in women it has no apparent effect in males (Davison, J. M., and M. D. Lindheimer, unpublished results, $n=4$ ). Thus perhaps hCG, to be effective, requires a known or unknown ovarian hormone, or hCG may merely be a marker or partial instigator of the altered milieu of pregnancy. The endocrine effects of administering hCG and the mechanisms involved in corpus luteum function and implantation are poorly understood. Still, in studies where this hormone has been used in the humans in an attempt to improve pregnancy rates after embryo transfer, it has become clear that maintenance or rescue of the corpus luteum during late luteal phase requires factors associated with a placenta within the uterus in addition to hCG (26-29).

Downward resetting of the osmostat, in the absence of hypovolemia or hypotension, has been reported in patients with carcinoma of the lung (6). As in pregnancy, the basic cause of the resetting is unknown, but may be related to hormones these tumors secrete that include hCG (30).

Thirst threshold has traditionally been designated at the $\mathbf{P}_{\text {osmol }}$ at which a subject experiences a strong conscious desire to drink (i.e., onset of severe thirst) (28). In our earlier study using such methodology the values for third trimester and 
Table V. Osmoregulation in the Third Trimester and Serially Postpartum in Two Gravidas (Patients K.T. and B.B.)

\begin{tabular}{|c|c|c|c|c|c|c|c|c|c|}
\hline & \multirow[b]{2}{*}{ Patients } & \multirow[b]{2}{*}{$\begin{array}{c}\text { Basal } P_{\text {oumol }} \\
\left(\mathrm{mosmol} \cdot \mathrm{kg}^{-1}\right)\end{array}$} & \multirow[b]{2}{*}{$\begin{array}{c}\text { Serum hCG } \\
\left(U \cdot m l^{-1}\right)\end{array}$} & \multicolumn{3}{|c|}{ Osmotic threshold for AVP release } & \multicolumn{3}{|c|}{ Osmotic thirst threshold } \\
\hline & & & & $\underset{\left(\mathrm{mosmol} \cdot \mathrm{kg}^{-I}\right)}{\mathrm{P}_{\text {oumol }}}$ & Slope & $r$ & $\begin{array}{c}\mathbf{P}_{\text {oemol }} \\
\left(\mathrm{mosmol} \cdot \mathrm{kg}^{-1}\right)\end{array}$ & Slope & $r$ \\
\hline \multirow[t]{2}{*}{ Third trimester } & K.T. & 280 & 15.6 & 274 & 0.18 & 0.85 & 291 & 0.59 & 0.96 \\
\hline & B.B. & 278 & 18.1 & 276 & 0.29 & 0.92 & 279 & 0.46 & 0.94 \\
\hline \multirow[t]{8}{*}{ Postpartum } & K.T. $(4)^{*}$ & 282 & 0.3 & 278 & 0.25 & 0.95 & 282 & 0.68 & 0.94 \\
\hline & B.B. (4) & 282 & 0.4 & 280 & 0.31 & 0.91 & 283 & 0.40 & 0.94 \\
\hline & K.T. (13) & 284 & 0.1 & 283 & 0.47 & 0.89 & 284 & 0.63 & 0.91 \\
\hline & B.B. (18) & 286 & ND & 287 & 0.51 & 0.93 & 288 & 0.51 & 0.90 \\
\hline & K.T. (42) & 288 & ND & 284 & 0.68 & 0.97 & 286 & 0.64 & 0.98 \\
\hline & B.B. (40) & 286 & ND & 287 & 0.59 & 0.94 & 289 & 0.52 & 0.87 \\
\hline & K.T. (95) & 289 & ND & 284 & 0.64 & 0.94 & 288 & 0.64 & 0.92 \\
\hline & B.B. (90) & 285 & ND & 286 & 0.55 & 0.88 & 289 & 0.50 & 0.91 \\
\hline
\end{tabular}

See Table II and text for explanation of derivation of terms. * Days after delivery.

postpartum women were 287 and $298 \mathrm{mosmol} \cdot \mathrm{kg}^{-1}$, respectively (2). That is $10-11$ mosmol $\cdot \mathrm{kg}^{-1}$ above the AVP secretory threshold. Recently it has been suggested that absolute thirst onset should be replaced by a value derived from serial assessment of thirst during hypertonic saline infusion (7). This is because thirst perception usually occurs gradually, probably in a progressive fashion over a wide range of plasma osmolalities, giving the investigator the opportunity to construct analogue scales that pinpoint the apparent threshold more accurately. A value derived in this manner by Thomson et al. (7) in nongravid subjects of $281 \mathrm{mosmol} \cdot \mathrm{kg}^{-1}$ was is in fact 4 mos$\mathrm{mol} \cdot \mathrm{kg}^{-1}$ less than the osmotic threshold for AVP release $(285$ mosmol $\cdot \mathrm{kg}^{-1}$ ) they obtained. Such results might infer that mild polyuria should be commonplace, which it is not. In the present study, the calculated method threshold was higher than that for hormone release both during and after gestation (range, 2 to $5 \mathrm{mosmol} \cdot \mathrm{kg}^{-1}$ ), thus fitting in more accurately with what is known about the physiology of the mechanism of thirst and urine concentration and dilution. Incidentally, thresholds were $11-13 \mathrm{mosmol} \cdot \mathrm{kg}^{-1}$ greater, by the "traditional" method (Table III, column 8), thus confirming our 1984 finding (2).

In conclusion, body tonicity decreases very early in gestation because the osmotic thresholds for both AVP release and thirst are significantly decreased by 5-8 wk of pregnancy. $P_{\text {osmol }}$ and the thresholds both remain at these new low levels for the remainder of gestation, but in late pregnancy the slope depicting the relationship between increments in $\mathbf{P}_{\text {osmol }}$ and levels of $P_{A V P}$ decreases, which could be due to a decrease in the sensitivity of the osmoreceptor system, increments in the MCR of AVP, or both. Observations of a markedly decreased threshold in a woman with a molar gestation demonstrated that the fetus is not necessary for the osmoregulatory changes in pregnancy, while data from this case as well as results observed in nongravid women treated with hCG suggest that hCG may play an important role in resetting the thresholds for AVP secretion and thirst during human gestation.

\section{Acknowledgments}

We thank Mrs. Irene White and Mrs. Elizabeth Arthur for excellent secretarial assistance. This work was supported by the Medical Research Council, Great Britain and National Institutes of Health.

\section{References}

1. Davison, J. M., M. B. Vallotton, and M. D. Lindheimer. 1981. Plasma osmolality and urinary concentration and dilution during and after pregnancy: evidence that lateral recumbency inhibits maximal urinary concentrating ability. Br. J. Obstet. Gynaecol. 88:427-479.

2. Davison, J. M., E. A. Gilmore, J. Durr, G. L. Robertson, and M. D. Lindheimer. 1984. Altered osmotic thresholds for vasopressin secretion and thirst in human pregnancy. Am. J. Physiol. 246:F105F109.

3. Durr, J. A., B. A. Stamoutsos, and M. D. Lindheimer. 1981. Osmoregulation during pregnancy in the rat. Evidence for resetting of the threshold for vasopressin secretion during gestation. J. Clin. Invest. 68:337-346.

4. Barron, W. M., J. A. Durr, B. A. Stamoutsos, and M. D. Lindheimer. 1985. Osmoregulation and vasopressin secretion during pregnancy in Brattleboro rats. Am. J. Physiol. 248:R29-R37.

5. Rolls, B. J., R. J. Wood, E. T. Rolls, H. Lind, W. Lind, and J. G. G. Ledingham. 1980. Thirst following water deprivation in humans. Am. J. Physiol. 239:R476-R482.

6. Robertson, G. L. 1984. Abnormalities of thirst regulation. Kidney Int. 25:460-469.

7. Thompson, C. J., J. Bland, J. Burd, and P. H. Baylis. 1986. The osmotic thresholds for thirst and vasopressin release are similar in healthy man. Clin. Sci. 71:651-656.

8. Whittaker, P. G., A. Taylor, and T. Lind. 1983. Unsuspected pregnancy loss in healthy women. Lancet. i:1126-1127.

9. Baker, R. J., and J. A. Nelder. 1978. The GLIM System (Release 3). Manual Numerical Algorithms Group for Royal Statistical Society, Oxford. 1-30.

10. Snedecor, G. W., and W. G. Cochran. 1967. Statistical Methods. Iowa State University, Ames, IA. 302.

11. Weitzman, R. E., and D. A. Fisher. 1977. Log linear relation- 
ship between plasma arginine vasopressin and plasma osmolality. $\mathrm{Am}$. J. Physiol. 233:E37-E40.

12. Rodbard, D., and P. J. Munson. 1978. Editorial comment. Am. J. Physiol 234:E340-E341.

13. Schrier, R. W., T. Berl, and R. J. Anderson. 1979. Osmotic and nonosmotic control of vasopressin release. Am. J. Physiol. 236(Renal Fluid Electrolyte Physiol. 5):F321-F332.

14. Robertson, G. L., P. Aycinena, and R. L. Zerbe. 1982. Neurogenic disorders of osmoregulation. Am. J. Med. 72:339-353.

15. Ganguly, A., and G. L. Robertson. 1980. Elevated threshold for vasopressin release in primary hyperaldosteronism. Clin. Res. 280:330A. (Abstr.)

16. Barron, W. M., B. A. Stamoutsos, and M. D. Lindheimer. 1984. Role of volume in the regulation of vasopressin secretion during pregnancy in the rat. J. Clin. Invest. 73:923-932.

17. Schrier, R. W., and J. A. Durr. 1987. Pregnancy: an overfill or underfill state. Am. J. Kid. Dis. 9:284-289.

18. Davison, J. M., E. A. Shiells, P. R. Philips, W. M. Barron, and M. D. Lindheimer. 1987. Metabolic clearance rates (MCR) of vasopressin (AVP) increase markedly in gestation: a possible cause of polyuria in pregnant women. Clin. Res. 35:646A.

19. Lindheimer, M. D., W. M. Barron, J. Durr, and J. M. Davison. 1987. Water homeostasis and vasopressin release during rodent and human gestation. Am. J. Kid. Dis. 9:270-275.

20. Bell, R. J., B. M. Laurence, P. J. Meehan, M. Congiu, B. A. Scoggins, and E. M. Wintour. 1986. Regulation and function of arginine vasopressin in pregnant sheep. Am. J. Physiol. 19:F777-F780.

21. Barron, W. M., J. A. Durr, and M. D. Lindheimer. Do hemodynamic factors mediate the osmoregulatory changes of pregnancy. Clin. Exp. Hypertens. B6:39A. (Abstr.).
22. Hay, D. 1985. Discordant and variable production of human chorionic gonadotropin and its free alpha and beta subunits in early pregnancy. J. Clin. Endocrin. Metab. 61:1195-1200.

23. Daya, S. 1987. Human chorionic gonadotropin increase in normal pregnancy. Am. J. Obstet. Gynecol. 156:286-290.

24. Reyes, F. I., J. S. D. Winter, and C. Faiman. 1985. Postpartum disappearance of chorionic gonadotropin from the maternal and neonatal circulations. Am. J. Obstet. Gynecol. 153:486-489.

25. Ho, P. C., L. C. Wong, and H. K. Ma. 1986. Plasma prolactin, progesterone, estradiol and human chorionic gonadotropin in complete and partial moles before and after evacuation. Obstet. Gynecol. 62:99-105.

26. Lenton, E. A., and R. Sulaiman. 1982. Plasma concentrations of human chorionic gonadotrophin from the time of implantation until the second week of pregnancy. Fertil. Steril. 37:773.

27. Casper, R. F., E. Wilson, J. A. Collins, S. E. Brown, and J. A. Parker. 1983. Enhancement of human implantation by exogenous chorionic gonadotropin. Lancet 2:1191.

28. Englert Y., M. Roger, J. Belaisch-Allart, M. Joudet, R. Frydman, and J. Testart. 1984. Delayed appearance of plasmatic chorionic gonadotropin in pregnancies after in vitro fertilisation and embryo transfer. Fertil. Steril. 42:835-840.

29. Mahadeven, M. M., A. Leader and P. J. Taylor. 1985. Effects of low-dose human chorionic gonadotropin on corpus luteum function after embryo transfer. J. In Vitro. Fert. Embryo. Transfer 2:190-194.

30. Gropp, C., K. Havemann, and A. Schener. 1980. Ectopic hormones in lung cancer patients at diagnosis and during therapy. Cancer 46:347-354. 